\section{Scientific freedom}

A group of Swedish scientists has recently formed a committee for scientific freedom which is to agitate on behalf of persecuted or harassed scientists in the same way that Amnesty International works for political prisoners. About 100 scientists have so far shown interest in the committee, which is chaired by Professor Ragnar Romanus of Gothenburg. The idea is that physicists will work on behalf of physicists, biologists for biologists, and so on.

The scientists say that their work will not in principle be directed at any particular countries. Several of the committee's members have previously urged the Soviet authorities to grant exit visas to Jewish scientists wanting to emigrate to Israel. They stress how- ever that they do not want to condemn any political system as such, but rather the treatment that various systems mete out to their scientists. At the moment, Argentina is an obvious target for their work.

\section{Hot summer, good news}

Infant mortality figures for England and Wales in 1976 show a marked improvement on figures for earlier years, and some of this improvement can probably be attributed to the long hot summer. Improvements in obstetric practice and care of newborn infants must also have had an impact, however, in the overall drop in mortality reported by the Office of Population Censuses and Surveys.

Post early neonatal mortality (one week to one year in age) regularly shows a seasonal term, but in 1976 this was exceptionally pronounced, summer deaths being 4.1 per thousand (annual rate) compared with 7.3 for the winter quarter. This helped in large part to cause a drop in the whole year's figures by an amount almost equal to the drop for all the previous five years.

Perinatal mortality ( 28 weeks after cenception to one week after birth) shows a much smaller seasonal term, but there too substantial gains have been recorded. 'The figure for 1970 was 23.5 per thousand; by 1975 it was down to 19.3 but in 1976 the figure dropped to 17.5 .

Infant mortality is now about half the level it was in the early 1950s, but until this past year many people have expressed concern that Britain's performance in reducing the rate did not match that in other developed countries.
A FEW years ago politicians were saying that British scientists were about to launch the "white hot technological revolution" which, fanned into flames by the efforts of the civil servants in a newly conceived Ministry of Technology, would revitalise British industry. The revolution, unfortunately, was stifled at birth, and the new Ministry soon disappeared.

Today Britain's scientists are blamed because the growth of industrial productivity is slow or nonexistent. They are castigated because they appear to be unwilling to follow careers in industry, or to direct their research into fields which might ensure economic progress. University courses for undergraduates and graduates are criticised for not imparting the proper skills, and even more for not giving the necessary "motivation". The country's most prestigious committees debate these subjects interminably, but have so far made no suggestions for improvements in education, training or organisation which engender any confidence in academic or commercial circles.

Yet thirty years ago British scientists enjoyed, and may even have deserved, greater prestige. It was generaily agreed that they had made many remarkable contributions of a very practical nature to both military and other problems (medicine, public health, transport for instance) during the Second World War. They showed themselves able to tackle and solve difficult and important problems often far removed from those they had previously studied. This they did for the most part with the minimum of expensive and complicated equipment, and often at very little cost to the community. This gave rise to the belief that if Britain increased her scientific establishment many fold, and if its financial support was allowed to grow exponentially (conditions ful-

\section{Effective science}

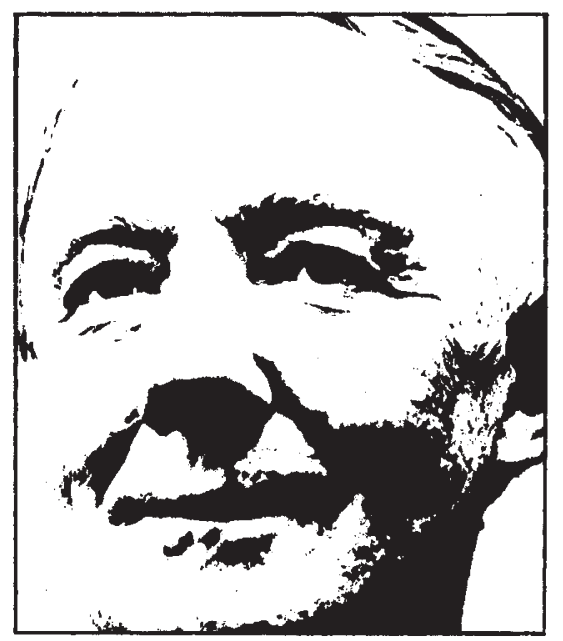

KENNETH MELLANBY

filled during more than twenty postWar years), she would solve many of her social and economic problems.

Unfortunately the results have been disappointing. Today all is not well with both science and industry in Britain and in many other parts of the world, and most attempts to diagnose and cure this malaise have been unsuccessful or have made things worse. Surely the obvious course would be to examine previous successes, and see what can be learned from them. For instance were there any common factors in their education, training and experience which made war-time scientists so adaptable and successful at solving so many of the immediately important problems which faced them and the country?

It is dangerous to generalise, but it is clear that many of those who were most successful in war-time science had previously worked only in university departments or for research councils. Their 'training' had been entirely academic, and, up till then, they had mostly worked in their own way on problems of their own choice. As far as I know, none had ever attended a course in 'management'. In many cases it was the scientists themselves who first became aware of the existence of the problems which they eventually tackled. They often had to convince the authorities, including the expert committee (which existed even then, but fortunately in much smaller numbers than today), that the work was worth doing. And it was often the academic scientists themselves who took the successful initiative in ensuring that their results were put into practice.

In many ways the problems facing the world today are as serious and urgent as those which faced Britain during the war. Can anyone explain why scientists no longer operate as effectively as they did at that time? There are far more trained research workers, and, notwithstanding recent cuts, far more money is spent on science. Surely this is what our committces should be investigating, even if they discover that it is often their own existence which is the barrier to scientific and economic progress? 